
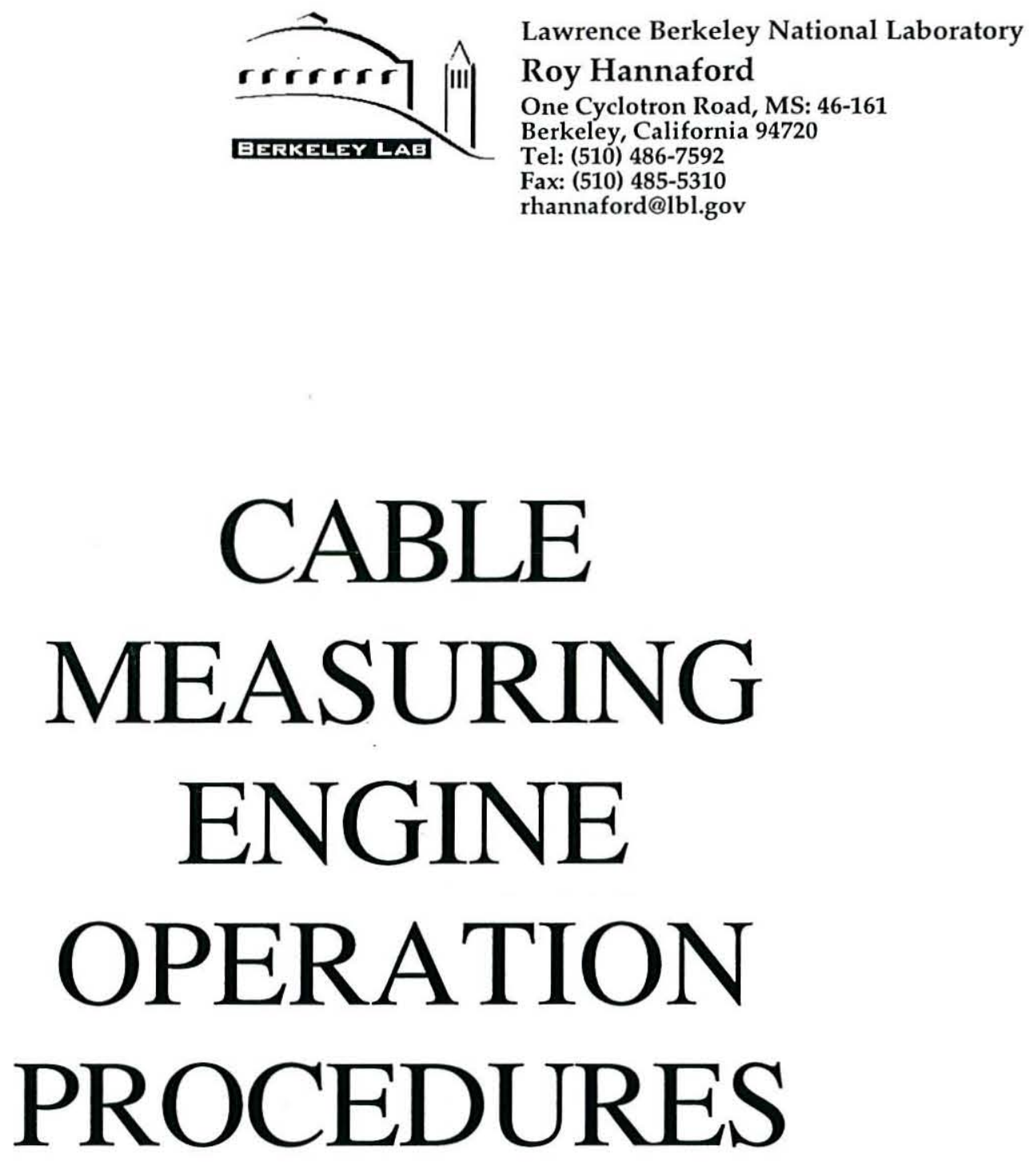

L B NL - 40565

SC-MA G-597 


\section{CABLE MEASURING ENGINE OPERATION PROCEDURES}

\section{INDEX}

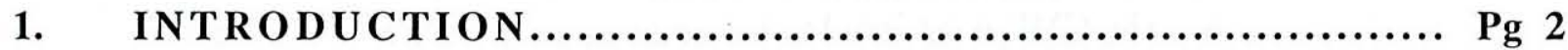

2. APPLICABLE DOCUMENTS.................................... 2

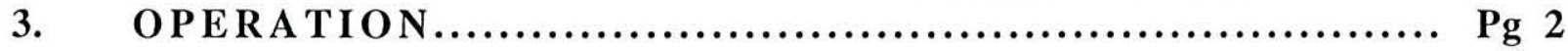

3.1 PREREQUISITES TO OPERATION …........................ Pg 3

3.2 CME PREPARATION FOR CABLE RUN ..................... Pg 3

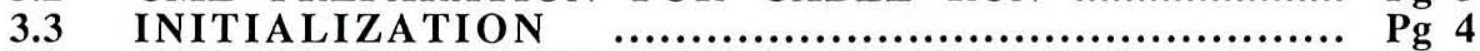

3.4 OBJECTIVES OF REAL-TIME CALIBRATION ............... Pg 4

3.4.7 (Real-Time Calibration Key Summary:) $\quad$........... Pg 4

3.5 CALIBRATION PROCEDURE …......................... Pg 5

3.6 START CABLE RUN ….............................. Pg 5

3.7 REAL-TIME GRAPHICAL PRESENTATION OF RUN DATA Pg 5

3.7.7 (Cable Run Key Summary:) …................... Pg 6

$3.8 \quad$ END OF CABLE $\quad$ RUN................................. Pg 7

3.8.8 (View Utility Key Summary:).................... Pg 8

4. LVDT CALIBRATION

(MAINTENANCE LEVEL and NEW MACHINES)..................... Pg 14

CALIBRATION DEVICE

(Fig 4-1)

$\operatorname{Pg} 16$

5. FINDING MACHINE CONSTANTS C1 and C2CL

(MAINTENANCE LEVEL and NEW MACHINES)..................... Pg 17

MACHINE CONSTANTS C1 and C2CL

(Fig

$5-1)$

6. FINDING C2-OFFSETs for the DIFFERENT CABLE TYPES

(MAINTENANCE LEVEL and NEW GAGES)......................... Pg 18

7. SET UP INSTRUCTIONS FOR FIXED GUIDE SLIDE

(Appendix A) .................................................. Pg

8. LVDT SET UP INSTRUCTIONS

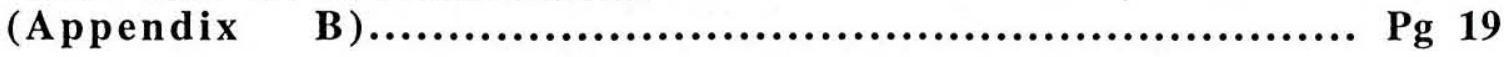

9. CleANing AND MAINTENANCE (Air Supply Specifications)..... Pg 20 


\section{CABLE MEASURING MACHINE OPERATION PROCEDURES}

\section{INTRODUCTION}

The Cable Measuring Engine (CME) is a tool which measures and records the cable dimensions in a nondestructive fashion. It is used in-line with the superconductor cable as it is being made. The CME is intended to be used as a standard method of measuring cable by the various manufacturers involved in the cable process.

\section{APPLICABLE DOCUMENTS}

\subsection{Applicability}

\subsubsection{CERN Documents}

\subsection{Source of Documents}

\subsubsection{LBNL Documents}

Superconducting Magnet Program

One Cyclotron Rd.

Berkeley, CA 94720

MS 46-161

(510) 486-6236

\subsection{Precedence}

In the event of conflict between the requirements of this specification and the above applicable documents, this specification shall take precedence. Any such conflict shall be brought to the attention of the LBNL Subcontract Administrator.

\section{OPERATION}

The CME is driven by a mechanical and electrical system. The mechanical function of the CME is operated by an air actuated hydraulic system. This system controls the pressure applied to the measuring head. The measuring head clamps the cable in two directions and travels with the cable flow when taking measurements. First, an edge load of $276 \mathrm{kPa}$ centers the cable in the head. Second, a load of $34,482 \mathrm{kPa}$ compresses the cable thickness. The cable is held at these pressures for a predetermined specified time, typically 4 to 5 seconds, allowing the dimensions to stabilize. Three Linear Variable Differential Transformers (LVDT's) are used to measure the position of the measuring head when clamped on the cable. The LVDT output, hydraulic pressure, and cable footage measurements are then sent to the computer for processing. Recorded measurements and calculated dimensions are displayed on the CRT, kept on disk, and printed on paper. 
LBNL-40565

\subsection{PREREQUISITES TO OPERATION}

3.1.1 The CME must only be operated by persons specifically trained in its use, as damage to the cable and the LVDT's may result.

3.1.2 The cable must be clean and free from chips, oil, and cable defects such as broken strands, fractured edges or cross overs.

3.1.3 The take-up spool or level winder must be capable of supplying approximately 178 Newtons of constant tension.

3.1.4 The cabling machine and the CME must be set up to allow the cable to enter the CME in the correct orientation. The cable travels from left to right and the cable major edge faces the operator.

3.2 CME PREPARATION FOR CABLE RUN

\subsubsection{Complete routine maintenance. (See Section 9 CLEANING AND} MAINTENANCE)

3.2.2 Keep measuring head free of dust and chips. Inspect all moving parts for proper lubrication and adjustment. Inspect hydraulic, pneumatic, and electrical lines for leaks or wear. Refill printer with paper, as needed.

\section{$3.3 \quad$ INITIALIZATION}

3.3.1 Turn on computer and run through program before cable is in measuring head. The computer program automatically displays the CME Main Menu screen (See Fig.1.). The Main Menu contains eight functions that the operator will use to start a cable run and retrieve the necessary CME data. At the beginning of a run execute the following procedures in sequence.

\subsubsection{Before any cable can be measured a CABLE TYPE FILE must} be made. If a cable type file already exists for the cable to be measured proceed to 3.3.3. The CABLE TYPE FILE holds all the necessary information about the cable to be measured. The file is made from the Main Menu, use the up down arrow keys to hi-light MAKE CABLE TYPE FILE and Press Enter. A CABLE TYPE FILE MAKER screen will appear, all eighteen fields must be completed before you can continue. The first field of the file name ext. must be the first letter of the Ordered By Code, and the second field a number 1-9, from the Cable Type Code. This follows the standard Cable Naming Convention, (SEE SSC-M35-000015, Rev.:1 for CABLE IDENTIFICATION CONVENTION). The Cable Type Title requires a minimum of 15 characters and will take a maximum of 40 . The Angle, Width and Thick Tolerances will default to the last Cable Type made, but may be changed. The $\mathrm{C} 2$ Offset is a constant that comes from the gage set to be used for each cable type.(SEE SECTION 6.1). Cable Thin, Thick and Width are the theoretical size of the cable to be measured. (Note: If the cable is flat, Thin \& Thick will be the same number.) Angle Nominal, Width Nominal , Thick Nominal and Pressure Nominal are the Ideal averages of the cable to be measured. Cal Gage SN\# is any 10 characters chosen to identify the certified calibration gage. 
3.3.2 Cal Gage Date, will be the date on the certification document for the calibration gage. Cal Gage Thin, Cal Gage Thick and Cal Gage Width will be the actual certified sizes on the certification document. (Note: If the gage is flat, Thin \& Thick will be the same number.) After the last field is entered you will be able to choose Edit, Create File or Abort. Edit will allow changes to the file. Create will save the file to be used later. And Abort will delete the file.

3.3.3 Select Normal Start or Restart and press Enter. This will display the Normal Start screen, Fill in the Supervisor's Name, Operator's Name and Cable ID. The Cable ID will be the Superconductor cable number which contains the following information, (SEE SSC-M35-000015, Rev.:1 for CABLE IDENTIFICATION CONVENTION) a three letter code of the organization that ordered the cable, cable type, strand vendor code, and a five digit chronological sequence number of the cable run. Fill in the clamp time, measurement interval, and reset counter to "0". The standard settings are displayed on (Fig. 2 \&3). Press Enter.

3.3.4 The Cable Type screen will appear. Select the cable type \#(S1, S2, S3, Etc.) and press enter. (See Fig. 4).

3.3.5 The Setup for Calibration screen will appear (See Fig. 5). Select the proper calibration gage and perform the calibration procedures per 3.5.

3.3.6 Fixed guide slide adjustment - (See Appendix A).

3.3.7 LVDT settings (See Appendix B). (See Fig. 6).

\subsection{OBJECTIVES OF REAL-TIME CALIBRATION}

3.4.1 The program may be exited at any time from the Real-Time routine by pressing the "F-10" key.

3.4.2 Provides an on-screen display of the actual dimensions recorded by the A/D board during calibration that will later be used to calculate cable dimensions. This overcomes the need to calibrate the panel mounted LED displays to the A/D board.

3.4.3 Calculates preset calibration values for any calibration gage block so that flat gage blocks can be used to make and record data in metric dimensions.

3.4.4 Provides indicators $(\mathrm{Hi} / \mathrm{Lo} / \mathrm{OK})$ that helps the user to quickly adjust the LVDT's to their proper values while clamped onto the calibration gage block.

3.4.5 The same clamp, unclamp keys ("C" for clamp, and "U" for unclamp) work with this routine to settle the LVDT's on the gage block.

3.4.6 Actual voltages are available to the user for diagnostic or investigative purposes by holding the ALT key down and pressing "V". They are hidden with the same key sequence. 


\subsubsection{Real-Time Calibration Utility Key Summary:}

To:

Continue After Calibrated

Exit to Main Menu

Clamp Measuring Head

Unclamp Measuring Head

Display A/D Voltages
Press:

Enter

F10

$\mathrm{C}$

$\mathrm{U}$

Alt-V

\subsection{CALIBRATION PROCEDURE}

3.5.1 Following the real-time calibration screen (See Fig. 7). Place the gage in the measuring head. The measuring head must be in the home position for calibration. The hydraulic pressure must be within $300 \mathrm{kPa}$ to successfully pass calibration. Press the run switch on the back panel before pressing enter to start calibration run. The CME will cycle automatically and measure the hydraulic pressure, angle, width, and thickness of the gage selected. The calibration data will appear on the screen (See Fig. 8). When completed, check to see if the calibration has successfully passed. If not, repeat calibration procedures. When "congratulations you passed" appears, press Enter to go to the cable run screen. (See Fig. 9).

\subsection{START CABLE RUN}

3.6.1 Use the "M" key to take one measurement on the flat gage and verify the gage size before feeding the cable through the measuring head. (If the CME is not reading the gage correctly re-calibrate the machine)

3.6.2 Make sure the electronic counter is down on the cable. You are ready to run cable, you can take a measurement anytime by pressing the "M" key. The measuring machine will automatically take readings at the Interval selected on the Start Screen. If a measurement is out of tolerance for one reading the alarm will sound. Turn off the audible alarm and make the adjustment indicated on the screen. Mark the cable in the out of tolerance region. If the measurements are within the specification for one reading the light will go off.

\subsection{REAL-TIME GRAPHICAL PRESENTATION OF RUN DATA}

3.7.1 The same graphical representation of data is available at the same time as the data is generated by the measuring machine.To access graphical charts press the space-bar to toggle between text and the graphical display. 
3.7.2 Individual "Go/NoGo" style indicators allow easy determination of whether any of the displayed parameters are out of tolerance.

3.7.3 Graph scales can be adjusted in order to view data that would otherwise be off-scale. The effect of the sensitivity adjustment is similar to that of a conventional strip graph recorder, allowing five discrete settings adjusted by

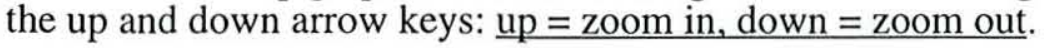

3.7.4 Graph can be adjusted individually, by selecting the desired graph with the "Page Up / Page Down" key. The selected graph is highlighted with a white border, while the un-selected graphs have a dim red border.

3.7.5 Initially, three selected parameters will be displayed on the screen, and one parameter will not be shown. The parameter displayed in any graph may be changed in sequence to allow viewing of any parameter in any graph by holding down the "CTRL" key and hitting "Enter".

3.7.6 During a cable run, the average of the points displayed on the screen is displayed with the current point value. The number of points shown on the screen may be increased or decreased in order to average more or less points, or simply to view more or less of the run at one time. To add more points to the display, press the right arrow key, to show fewer points, press the left arrow key.

3.7.7 Cable Run Key Summary:

To:

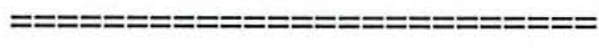

View Text/Graphics

Exit to Main Menu

Measure Cable

Decrease \# of points shown

Increase \# of points shown

Change Adjust Plot

Change Displayed Parameter

Increase Sensitivity (Zoom In)

Decrease Sensitivity (Zoom Out)
Press:

$\begin{aligned} & \text { Press: } \\ & \text { Space-Bar } \\ & \text { F10 } \\ & \mathrm{M} \\ & \text { Left Arrow } \\ & \text { Right Arrow } \\ & \text { Page Up / Page Down } \\ & \text { CTRL-Enter } \\ & \text { Up Arrow }\end{aligned}$

Down Arrow 
Additional software is provided to view old data files in the same graphical format as well as perform statistical calculations for any run, or section of a run. When the cable run is complete, stop the cable machine, and complete these steps:

3.8.1 To load Data Files press F10 to return to the Main Menu. From the Main Menu use the arrow keys to select Display Run Data on Screen and press Enter. This automatically prompts Data Cmeview Utility. From this screen use the up/down arrow keys to select the Cable Run \# to view and press Enter. When the file is loading, the individual points are displayed as they are read with their numeric value and the appropriate "Go/NoGo" marker. The number of points shown on the screen is always the total number of points in the run.

\subsubsection{Cursor Movement:}

Immediately following the data load procedure, the middle point in the run will be highlighted to designate that point as the cursor point. By pressing the left-arrow or right-arrow keys, the cursor point can be moved to any point on the screen. While the cursor moves, the Current Value and Go/NoGo displays are updated to reflect the cursor point data. To allow long moves through the data, holding the "CTRL" key down and pressing the left or right arrow keys will move the cursor to the first or last point in the run.

\subsubsection{Statistical Calculations:}

When the data is first read, a green begin-marker and a red end-marker are displayed to identify the largest in-tolerance section of cable. These markers may be moved, as explained below. By pressing the space-bar, some simple statistics will be displayed for the section of cable between the beginmarker and end-marker, i.e. Average, Maximum, Minimum, Standard Deviation. (Note: If there are no points in tolerance, the begin-marker will be placed at the first point in the run, and the end-marker will be placed at the last point in the run.)

\subsubsection{Begin/End Markers:}

At any time after the data has been completely displayed on the screen, the begin/end markers can be moved as follows: Hit the "Home" or "End" keys to move to the begin or end markers. This is not a necessary step, but may be helpful in avoiding long moves through the data. Position the cursor at the point where the begin or end marker is desired and, while holding the "CTRL" key hit the "Home" or "End" key, depending whether a begin or an end marker is desired. After moving the end points, hitting the space-bar will re-calculate cable statistics for the newly selected section.

3.8.5 When the graph is organized to show the statistics for the entire in tolerance section of the run, simply press the Print Screen key to print the graph to the printer. After the graph is printed, press the Space Bar to display the statistics for the run. When the statistics are on the screen press the Print Screen key to print the statistics for the run.

(NOTE: be sure the printer is on line and is set at top of form). 
3.8.6 From the Main Menu, load a floppy disk in A drive and format it.

3.8.7 From the Main Menu, copy the run data to the diskette in drive A.

3.8.8 View Utility Key Summary:

To:

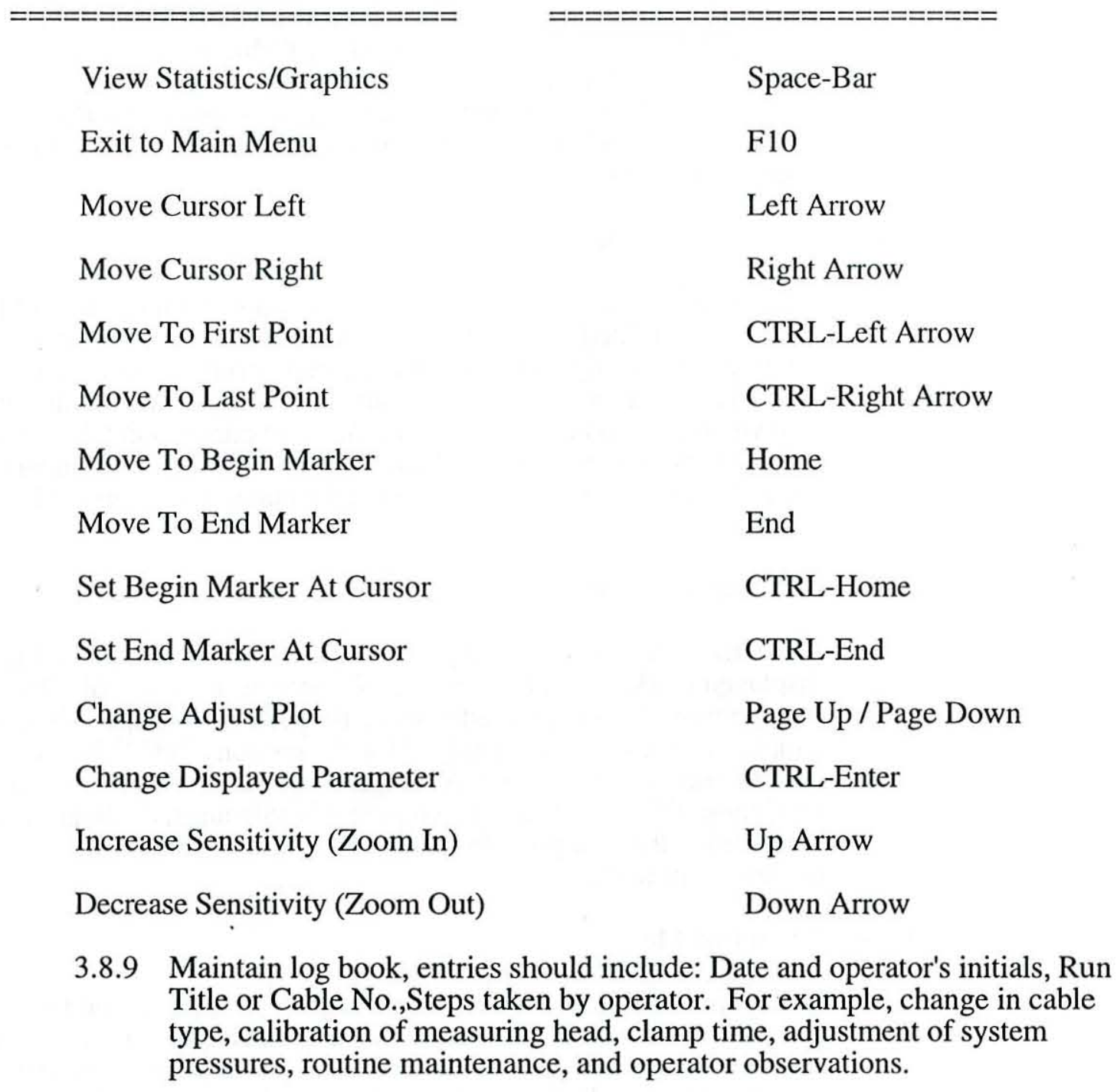


NORMAL STARTUP

RESTART

Display Run Data on Screen

Print Run Data to Printer

Copy Run Data Diskette (Drive A)

Display Directory of Disk in Drive A

Make New "Cable Type" File (CMECType.\#\#)

Format a Diskette (Drive A)

Use Arrow Keys to Highlight Selection - Then press ENTER

NORMAL START

[CME $\mathrm{XXX}$ ]

Fig. 2

Date: $\quad 04-19-93$

Machine ID\#

Time: $\quad 03: 59: 59$

\section{CME\#6}

Supervisor Name: ROY HANNAFORD

Operator Name: ROY HANNAFORD

Cable ID: $\quad$ SSC - 3 - I - 12345

Cable LOG: S3I12345.SSC

Log Interval: 10 Meters $\quad$ Clamp Time: 4 seconds

Counter Preset: 0000 Meters

Would like to edit this screen $<\mathrm{Y} / \mathrm{N}>$ : 
RESTART

[CME XXX]

Fig. 3

Date: $\quad$ 04-19-93 Machine ID\# $\quad$ Time: $03: 59: 59$

CME\#6

Supervisor Name:

ROY HANNAFORD

Operator Name:

ROY HANNAFORD

Cable ID:

SSC - 3 - I - 12345

Cable LOG:

S3I12345.SSC

Log Interval: 10 Meters Clamp Time: 4 seconds

Counter : 0000 Meters Data Point \# 1234

Would like to edit this screen $<\mathrm{Y} / \mathrm{N}>$ :

CABLE TYPES

Fig. 4

Type S1: $\quad 23$ Strand SSC Inner Coil (9.30mm)

Type S2: $\quad 30$ Strand SSC Outer Coil $(9.73 \mathrm{~mm})$

Type S3: $\quad 30$ Strand $50 \mathrm{~mm}$ INNER $(12.34 \mathrm{~mm})$

Type S4: $\quad 36$ Strand 50mm OUTER $(11.68 \mathrm{~mm})$

Last cable type measured was:

30 Strand SSC Inner Coil (12.34mm)

Select Desired Cable Type: 
Cable Type: $\quad 30$ STRAND 50mm INNER (12.34mm)

Calibration Gage: $\quad$ \#B30-0.0318

THE MEASURING HEAD FIXED GUIDE SLIDE MUST BE ADJUSTED

Adjust according to Appendix A

PRESS START BUTTON \&CONFIRM RUN LIGHT IS LITE

Press "Enter" to Continue

F10 to Abort

LOW -1.657 LVDT- $0-\mathrm{mm}$. Nominal Value: $-1.677( \pm 0.010)$

LOW +1.657 LVDT- $1-\mathrm{mm}$. Nominal Value: $+1.677( \pm 0.010)$

HIGH -0.050 LVDT- $2-\mathrm{mm} . \quad$ Nominal Value: $-0.030( \pm 0.010)$

LOW $\quad-0 \quad$ PRESSURE - $\mathrm{kPa} \quad$ Nominal Value: $17182( \pm 300)$

"C" to Clamp "U" to Unclamp "Enter" to Continue "F10" To QUIT 


\begin{tabular}{|c|}
\hline $\begin{array}{l}\text { Cable Type: } \\
\text { Calibration Gage: } \quad \text { \#B30-0.0318 STRAND 50mm INNER (12.34mm) }\end{array}$ \\
$\begin{array}{c}\text { Calibration requires ten clamping cycles } \\
\text { (cycling is automatic) }\end{array}$ \\
Place calibration gage in the measuring head \\
(serial number facing up) \\
Measuring head must be in the "Home" position
\end{tabular}

Press "Enter" to Continue

F10 to Abort

CALIBRATION SSC 3-I-12345

Fig. 8

DATE 04-19-1993

TIME 03:59:59

30 STRAND 50mm INNER (12.34)

CME \#5

$\begin{array}{clllll}\text { POINT } & \text { METERS } & \mathrm{kPa} & \text { ANGLE } & \text { WIDTH } & \text { THICK } \\ & & & & & \\ 1 & -- & 17182 & -.000 & 12.34 & 1.458 \\ 2 & -- & 17182 & -.000 & 12.34 & 1.458 \\ 3 & -- & 17182 & -.001 & 12.34 & 1.458 \\ 4 & -- & 17182 & -.001 & 12.34 & 1.458 \\ 5 & -- & 17184 & -.001 & 12.34 & 1.458 \\ 6 & -- & 17182 & -.001 & 12.34 & 1.458 \\ 7 & -- & 17186 & -.001 & 12.34 & 1.458 \\ 8 & -- & 17182 & -.001 & 12.34 & 1.458 \\ 9 & -- & 17182 & -.001 & 12.34 & 1.458 \\ 10 & -- & 17187 & -.002 & 12.34 & 1.458\end{array}$

CONGRATULATIONS YOU PASSED THE CALIBRATION TEST!

Press "Enter" to Continue 
F10 to Abort

CABLE RUN S3I12345

Fig. 9

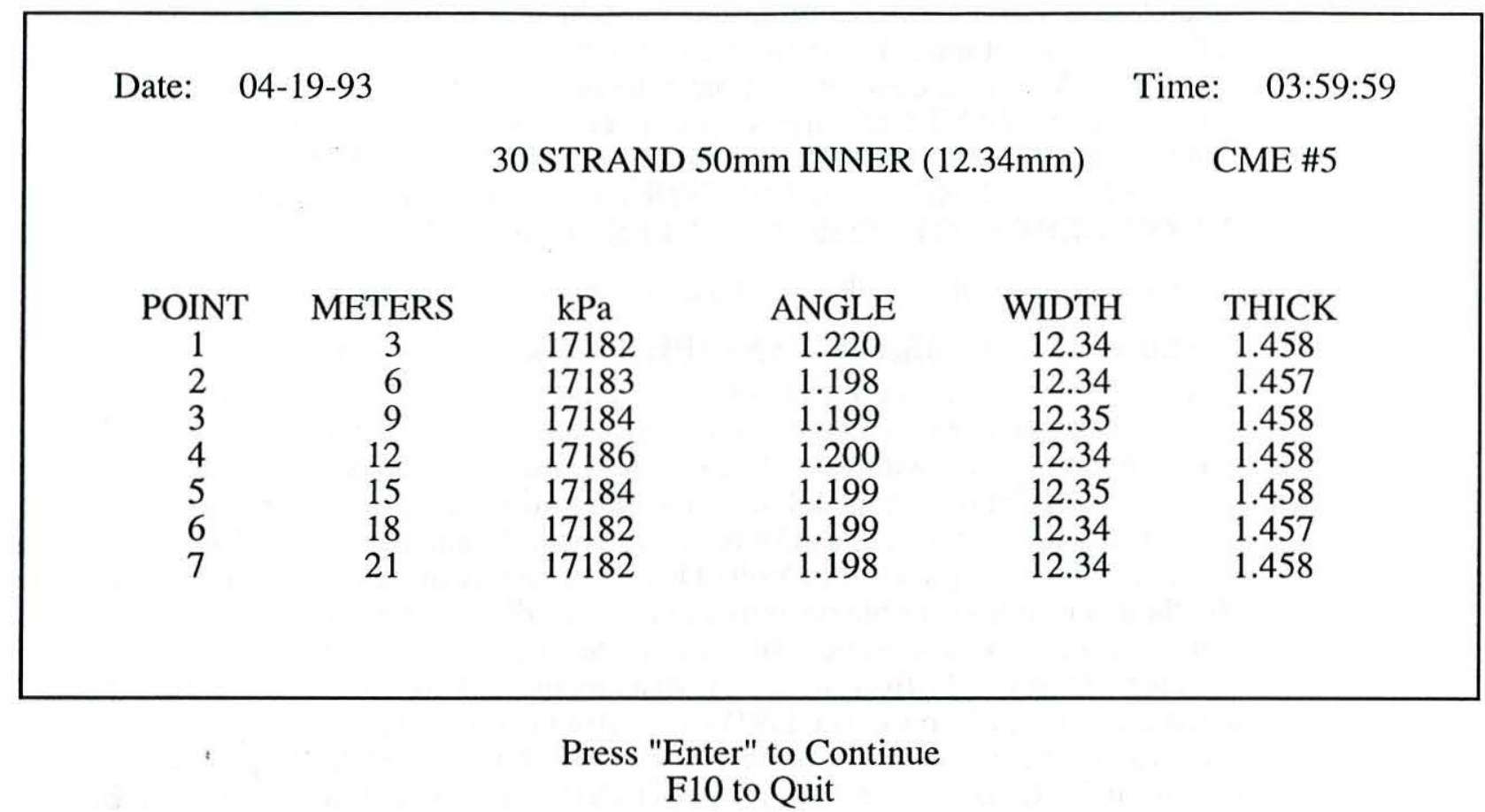




\section{LVDT CALIBRATION (MAINTENANCE LEVEL and NEW MACHINES)}

4.1 Run the CMEPOLY.EXE whenever an LVDT, LVDT Amplifier, or the Metrabyte board are changed.

4.2 Each LVDT has it's own calibration curve which is an important part of the calculated data output. The calibration should be checked periodically. When changing LVDTs, re-calibrate and have the new calibration curve coefficients put into the CONSTANT.CME file for the specific location of the LVDT. LVDT CALIBRATIONS ARE PERFORMED ON A CALIBRATION STAGE AND SHOULD NOT BE PERFORMED WITHOUT HAVING KNOWLEDGE OF THE PROCESS. (see fig.4-1)

4.3 Turn on the computer on the (CME) and exit the menu by using the Esc key.

4.4 Set the LVDT Amplifiers (SPAN), (PHASE) \& (ZERO) for a \pm range on LVDT (\# 0,1 of $\pm 2.54 \mathrm{~mm}$ ) and LVDT (\# 2 of $\pm 2.54 \mathrm{~mm}$ or $1.52 \mathrm{~mm}$ ). After installation and connection of the transducer, amplifier, and display, turn the power on and allow 30 minutes for warm-up. Remove all LVDTs from the measuring head and starting with LVDT \# 0, install \#0 in the calibration device (as shown in Fig. A). Electrically disconnect the LVDT from the amplifier and turn the ZERO adjustment for an indicated output of zero Volts DC. Reconnect the LVDT to the amplifier. Set the micrometer thimble on zero and use the adjustable indicator base to set the output as close to zero as possible. Lock the indicator base. This is the null position of the LVDT from which the displacements will be measured. Using the micrometer thimble, move the LVDT core from the null position to approximately half way to the transducer's full scale position. Turn the SPAN adjustment for an output of 50 to $60 \%$. Now adjust the PHASE control to obtain a maximum meter reading. Use the SPAN control, if necessary to keep the reading between 50 and $100 \%$. Move the LVDT core back to the precise null position (0 on the micrometer thimble). If necessary, adjust the ZERO control until the output reads zero. Move the LVDT, again, from zero to exactly plus full scale displacement. Turn the SPAN control until the output reads the desired full scale output. Repeat the ZERO and SPAN adjustments if necessary. If unable to adjust, refer to the LVDT Amplifier (ATA-101) book for further help.

4.5 From DOS run CMEPOLY.EXE. Set the micrometer thimble on zero so there is .200" travel in both directions. With the micrometer thimble on " 0 " and the LVDT clamped in the calibration device use the adjustable indicator base to set the LVDT to "0".

4.6 At the prompt, LVDT no.? answer $\mathbf{0 , 1}$ or $\mathbf{2}$ 
4.7 The LVDTs are calibrated in $.127 \mathrm{~mm}$ steps.

LVDT 0 \& 1 have $2.413 \mathrm{~mm}$ range and we start at $-2.413 \ldots 0 \ldots+2.413=\mathbf{3 9}$ points.

LVDT 2 may have a $1.524 \mathrm{~mm}$ range and we start at $-1.397 \ldots 0 \ldots+1.397=23$ points.

Rotate the thimble to the starting ( - no. for the LVDT being calibrated) work from the - no. thru 0 , to + no. in $.127 \mathrm{~mm}$ increments. These increments are read on the micrometer thimble (not the LVDT readout).

4.8 At the prompt, \# of data points to take? answer $\mathbf{3 9}$ or $\mathbf{2 3}$

4.9 Rotate the thimble to the starting - no. for the LVDT being calibrated, then enter the value using the - and + symbols in the entry and press enter.

4.10 At the end of the entries, type 0 to skip editing or follow the instructions on the screen to edit a data point. The program will do a polynomial fit to the data entered and will give a new set of coefficients for that gage. Write down these new coefficients or do a print screen to have a hard copy of these numbers. Answer yes (Y) to, DO YOU WANT TO UPDATE MCONST.CME. Repeat this operation for all LVDTs and exit the CMEPOLY.EXE program. 


\section{CALIBRATION DEVICE FOR LVDTs}

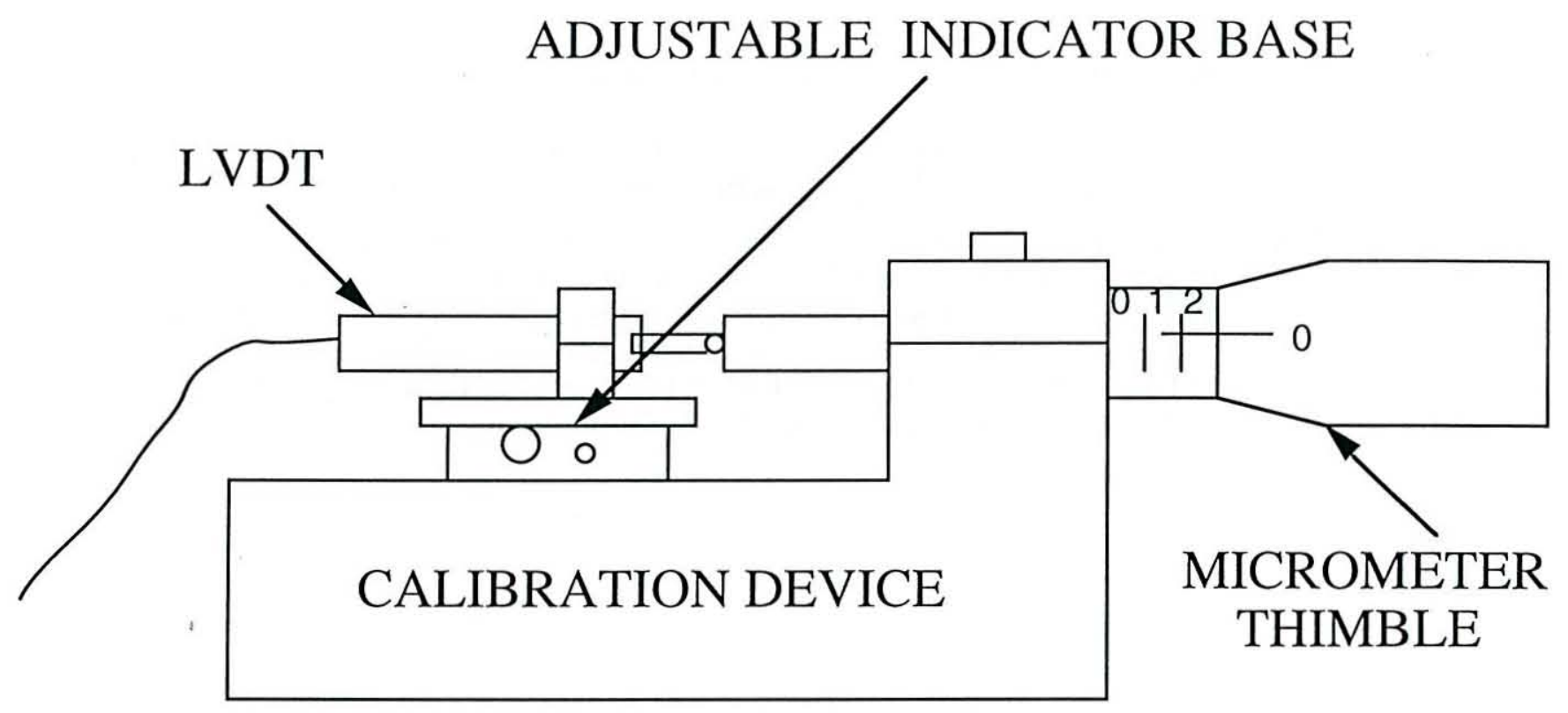

fig.4-1 


\section{FINDING MACHINE CONSTANTS C1 and C2CL (MAINTENANCE LEVEL and NEW MACHINES)}

5.1 Finding $\mathrm{C} 1$, with the measuring head removed from the compression cage, remove all LVDT's. Install a $9.5 \times 50 \mathrm{~mm}$ long dowel pins in the LVDT holders for LVDT0 and LVDT-1. With a large metric micrometer, measure across the dowel pins below the clamps.(read to 0.XXX) Subtract from this measurement $9.5 \mathrm{~mm}$ to give you a center to center distance of the LVDT's. (see fig.5-1) This is the C1 constant dimension, it should be approximately $158.115 \mathrm{~mm}$. Record this number for future reference.

5.2 Finding $\mathrm{C} 2 \mathrm{CL}$, With the measuring head removed from the compression cage, remove the following parts. Part \# 22K3534 Gaging Head Guide - left hand, Part \# 22K3503 Gaging Head, Part \# 22K3213 Gaging Bar. With any set of slot blocks installed, place a precision ground $19 \mathrm{~mm} \times 19 \mathrm{~mm} \times 177 \mathrm{~mm}$ long SQUARE TOOLING BLOCK against the flat side of the slot blocks (see fig.B-1). With a large metric micrometer, measure across the dowel pin in the LVDT-0 holder and the $19 \mathrm{~mm}$ TOOLING BLOCK. Subtract from this measurement half the dowel pin, or $4.75 \mathrm{~mm}$ and the $19 \mathrm{~mm}$ TOOLING BLOCK. This is the C2CL constant dimension, it should be approximately $91.948 \mathrm{~mm}$. Record this number for future reference.

5.3 Enter these new constants for $\mathrm{C} 1$ and $\mathrm{C} 2 \mathrm{CL}$ in the MCONST.CME file of the CME program. 


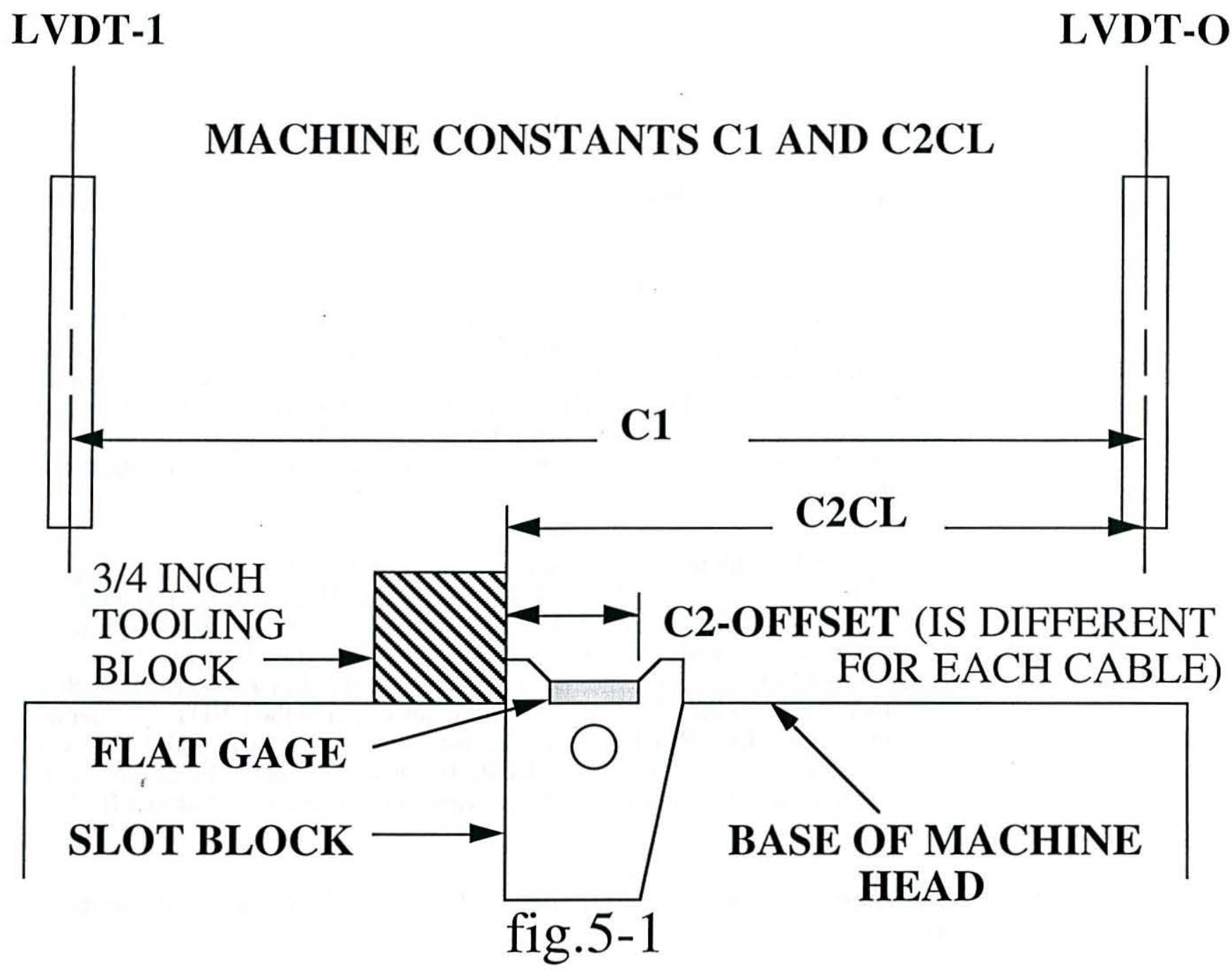

6. FINDING C2-OFFSETs for the DIFFERENT CABLE TYPES (MAINTENANCE LEVEL and NEW GAGES)

6.1 The C2-OFFSET is different for each cable type. The C2-OFFSET is a constant that is used in the CMECTYPE.XX files of the CME program. The best way to take this measurement is to simply measure the width of the back straight leg of both slot blocks of a particular gage set and find the average of the two, now add that dimension to the width dimension of the mating flat gage for that set. This is the C2-OFFSET constant dimension.

6.2 Enter these new constants for the C2-OFFSETs in the CMECTYPE.XX files of the CME program. Each CMECTYPE.XX file should have a different C2OFFSET. 


\section{Appendix A}

\section{SET UP INSTRUCTIONS FOR FIXED GUIDE SLIDE}

7.1 Make sure the machine run light is OFF.

7.2 Loosen the two vertical hold down screws and the two horizontal back up screws on the fixed guide slide.

7.3. Pull fixed guide slide as far back as possible.

7.4. Select the calibration gage and the appropriate slot block for the cable to be measured.

7.5. Wipe as clean as possible all gaging surfaces, blocks, gages, and fingers of guide slide. Make sure the gage head is free from dirt or grit. Blow out with compressed air.

7.6. Place slot blocks in their appropriate ' $v$ ' notch, with numbers out. Slide flat calibration gage through slot blocks and measuring head with numbers up.

7.7. Make sure all gages stay flat and seated in position. Push fixed guide slide with finger pressure against gage and tighten vertical hold down screw. Carefully adjust horizontal back up screw until it touches the guide slide. (Do not over tighten).

7.8. Remove calibration slot block and return to their protective case.

7.9. Fixed guide slide is now set for the desired cable type.

\section{Appendix B}

\section{LVDT SET UP INSTRUCTIONS}

8.1 Loosen lock screws on adjustable indicator bases for all three LVDT's, and back them clear of moving parts.

8.2 Clamping measuring head on selected calibration gage. Press " $\mathrm{C}$ " to clamp and "U" to unclamp. (Make sure all gage surfaces are clean).

8.3 Set each LVDT to the value displayed on the computer screen. Lock securely in place with lock screws on indicator bases.

8.4 Unclamp head. (DO NOT ALLOW HEAD TO BOTTOM OUT ON LVDT'S).

8.5 Clamp and unclamp head several times to insure LVDT readings' fall within tolerance range.

8.6 LVDT's are now set for specific wire type. 


\section{CLEANING AND MAINTENANCE}

\subsection{AIR SUPPLY SPECIFICATIONS}

The CME requires an air source capable of supplying $30 \mathrm{cfm}$ of clean, dry, compressed air at a pressure of $120 \mathrm{psi}$. In humid climates, it may be necessary to install a refrigerated compressed air dryer at the compressor.

\subsection{GAUGE HEAD CLEANING \& MAINTENANCE}

These cleaning and maintenance procedures make reference to the following drawing: $22 \mathrm{~K} 3456$

(IMPORTANT) Before proceeding with cleaning and maintenance of the CME, ensure that air and electrical power are turned off. Wear lint-free gloves for reassembly. Do not use any sandpaper or stone on gauging surfaces. Clean contaminated surfaces with Scotch-Brite or fine steel wool, then wipe and blow completely clean with compressed air. Lubricate moving surfaces with light oil.

9.3 DISASSEMBLY AND CLEANING (Reference drawing 22K3456)

9.3.1. Loosen 3 screws (item 73) and remove 3 LVDTs (Item 55) from LVDT mounts (Item 19). (Note orientation of LVDTS to ensure proper reassembly later). Hang LVDTs on Nylatrac hose carrier for safe storage.

9.3.2. Loosen 4 head bolts (Item 43) until lock washers are free to move.

9.3.3. Loosen 4 screws (Item 78) in hook clamp assemblies.

9.3.4. Remove 2 hook clamp assemblies (Items 77, 78, and 81) at front of gauge assembly.

9.3.5. Remove 2 locating pins (Item 15) from left and right of gauge assembly.

9.3.6. Remove 2 head bolts and washers (Item 43 and 44) at front of gauge assembly.

9.3.7. Shift position of 2 gauge plate spacers (Item 30) at front of gauge assembly as necessary to allow removal of gauge base (Item 5) assembly. 4 compression springs (Item 51) in gauge plate spacers will raise the gauge top plate (Item 2) slightly to allow access to the gauge base assembly. Remove gauge base assembly. (WARNING) The springs in the gauge plate spacers are tightly compressed. If the front gauge plate spacers are removed completely, the springs may escape with sufficient force to cause injury. Exercise caution if you decide to remove front gauge plate spacers.

9.3.8. Remove 4 screws and washers (Items 49 and 58) and 2 end stop bars (Item 25). Note orientation of end stop bars to ensure proper re-assembly later.

9.3.9. Remove 2 retainer springs (Item 17) from spring mount buttons (Item 16). 
9.3.10 Remove 8 screws and washers (Item 48 and 49) from gauging head guides (Item 27 and 28).

9.3.11. Remove left and right gauging head guides (Item 27 and 28). Note orientation of gauging head guides to ensure proper re-assembly later.

9.3.12. Remove gauging head (Item 24). Note orientation of gauging head to ensure proper re-assembly later.

9.3.13. (This step is optional. Disassembly is not normally required.) Remove 2 wishbone springs (Item 18) from small spring buttons (Item 26).

Remove 2 retainers (Item 22), damping plunger (Item 14), and spring (Item 69). Note orientation of gauging lever to ensure proper re-assembly later. Damper plunger and spring (Items 14 and 69) are oriented on the right side of the head as shown on the rear view on Dwg.\# 22K3456C.

9.3.14. Remove 2 shoulder bolts (Item 50) from gauge slide. Note location of each shoulder bolt to ensure proper re-assembly later. Bolts are matched to location and must be re-assembled in proper location.

9.3.15. Remove 2 screws and washers (Items 53, 83, and 84) from pivot guide slide assembly (Item 4).

9.3.16. Remove gauge slide (Item 21), pivot guide slide assembly, and 4 gauge slide springs (Item 23).

9.3.17. Inspect all parts carefully for contamination, corrosion, and wear. Clean thoroughly with compressed air before re-assembling. Lubricate moving surfaces with light oil.

\section{$9.4 \quad$ RE-ASSEMBLY}

9.4.1. Install gauge slide (Item 21), pivot guide slide assembly (Item 4), and 4 gauge slide springs (Item 23). Ensure that springs are properly seated in the slide assembly. Lubricate moving surfaces with light oil.

9.4.2. Install 2 shoulder bolts (Item 50) and 2 screws and washers (Item 53,83 and 84 ) in their original locations.

9.4.3. Re-assemble (if disassembled) damping plunger (Item 14), spring (Item 69), retainers (Item 22), and wishbone springs (Item 22).

9.4.4. Install gauging head (Item 24) with the damper plunger and spring (Items 14 and 69) oriented on the right side of the head as shown on the rear view on Dwg.\# 22K3456C.

9.4.5. Install left and right gauging head guides (Item 27 and 28) with 8 screws and washers (Items 48 and 49). While installing and tightening the screws, gently press the left and right gauging head guides together to achieve a snug sliding fit for the gauging head. Lubricate moving surfaces with light oil.

9.4.6. Install the 2 retainer springs (Item 17). 
9.4.7. Install the 2 end stop bars (Item 25) with the 4 screws and washers (Items 49 and 58).

9.4.8. Ensure that both the gauge base assembly and the gauge base plate (Item 1) are clean and free of dust before installing the gauge base assembly.

9.4.9. Install 2 locating pins (Item 15).

9.4.10. Install 2 hook clamp assemblies (Items 77, 78 and 81) at front of gauge assembly.

9.4.11. Tighten 4 hook clamp assemblies.

9.4.12. Move 2 gauge plate spacers (Item 30) back into position with flats oriented as shown on Dwg.\# 22K3456C. Install 2 bolts and washers (Items 43 and 44). Tighten bolts with 80-85 foot-pounds torque.

9.4.13. Install the 3 LVDTs in the same orientation as they were removed in the LVDT mounts.

9.4.14. (IMPORTANT) Perform normal set-up and calibration with the appropriate master set bar. (see sections 3.3, 3.4, 3.5)

9.4.15. With the appropriate master set bar in place, make a test run of the CME for a minimum of 100 clamping cycles. 


\section{SUPERCONDUCTING CABLE IDENTIFICATION CONVENTION}

The following naming convention shall be used for identifying superconducting cable

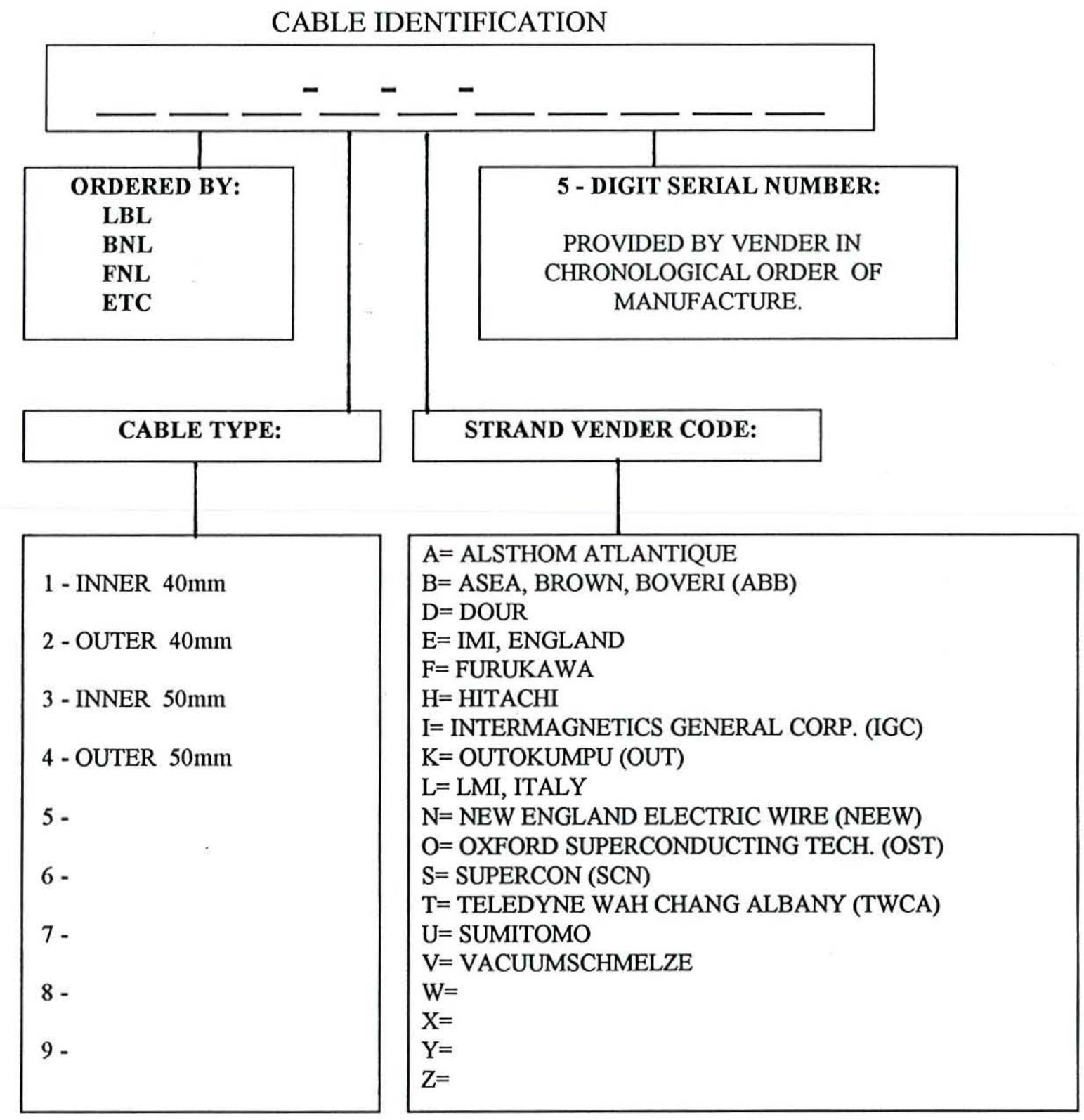


LEGAL NOTICE

This report was prepared as an account of work sponsored by the United States Government. Neither the United States nor the Department of Energy, nor any of their employees, nor any of their contractors, subcontractors, or their employees, makes any warranty, express or implied, or assumes any legal liability or responsibility for the accuracy, completeness or usefulness of any information, apparatus, product or process disclosed, or represents that its use would not infringe privately owned rights. 